\section{A Doctor's Guide to Court}

Keith Simpson. Pp. ix +174 with 11 illustrations. London: Butterworths. 1962. 30s.

The subtitle is 'A handbook on medical evidence'; and the author's declared aim is to "reassure the doctor in his preparation for court attendance and make him a better witness". The bare facts given could be quarried, with sturdy and application, from standard textbooks; here they are ready marshalled for those with little time to spare, and provided with a continuous background of comment and sage advice, the fruit of long experience. A businesslike touch which typifies the general approach is that illustrations are given only where they convey essential information; those who relish pictorial horrors must search elsewhere. Appendices include ten pages of useful tables and nomograms, dealing with centres of ossification, blood group frequencies, body surface area and similar matters; and a glossary of legal terms.

In short, this is a portable, readable, and practical book; and any doctor who is faced with the prospect of a visit to court would do well to mortgage his fees as a witness (chapter 7 sets these out in detail) and buy it.

\section{A History of the Royal College of Physicians of Ireland, 1654-1963}

J. H. D. Widdess. Pp. xii +255 , illustrated.

Edinburgh and London: E. \& S. Livingstone.

1963. $40 \mathrm{~s}$.

It is almost a century since any attempt has been made to sift a connected narrative from the accumulated papers relating to the Royal College of Physicians of Ireland. The College evolved from the Fraternity of Physicians founded in 1654 by John Stearne, and its Royal Charter was granted by King Charles II in 1667 after protracted negotiations throughout the Restoration period and almost 150 years after Henry VIII's foundation of the Royal Colleges of Physicians of London. The Charter purported "to erect in our City of Dublin, in that our Kingdom a college society and incorporative of Physicians, according to the rule and form of the Charter heretofore granted to the Physicians of our City of London ....", to control practice in the city and outside within a radius of 20 miles. Dublin at that time was a City of six parishes without walls and with less than 9,000 inhabitants, but its expansion was rapid following upon the Restoration and "polite learning and the sciences also benefited from more peaceful conditions". It was in this period that Dr. Patrick Dun, whose name is well known today in Dublin, within the college and without, as it was in his lifetime, was elected President of the College in 1681. It was probably Dun whose influence induced the College to) petition fo: the new Charter granted in 1692 to "reform the inconveniences and abuses ... . whereby the number of unskilful and illiterate practicers of physic had increased, the frauds and deceits of empirics, apothecaries and druggists do abound to the dishonour of the government and the loss and destruction of their Majesties good subjects in this Kingdom". Patrick Dun, as first President of the new College, presented the folio of Charter, Bylaws and records now known as Dun's Book. He had a profound influence on medical practice and medical teaching in his time, and on the fortunes of the College. However, he is but one in the long roll of great medical men who have been Presidents and Fellows of "this ancient institution", and whose lives, and original contributions to medicine have been explored by Professor Widdess. This is a scholarly and comprehensive historical review; the book is well produced, in clear print, and has some beautiful illustrations. It should be warmly welcomed, especially by the Fellows and Members of the Irish College.

\section{Neurometabolic Disorders in Childhood}

Proceedings of a Symposium held at Sheffield in May 1963. Edited by K. S. HoLT and J. Milner. Pp. 112, illustrated. Edinburgh \& London: E. \& S. Livingstone. 1963. 15s.

Nowdays it is the custom for the proceedings of every symposium of any importance to be published and the reader is spared nothing from the pompous opening remarks of the chairman to the disjointed verbatim account of the discussions which follow the communications. By the time such proceedings appear in print they are often out of date and make disappointing reading.

The present volume is the exception that proves the rule. The papers are of a uniformly high quality and ihis small volume brings together data of importance that could not easily be collected from their sources. This applies particularly to the papers in the first part, which deal with such general topics as the biochemical aspects of child neurology (K. S. Holt), the biochemical aspects of disorders of mood (T. A. Jenner), the biochemical aspects of intelligence (J. Stern) and the neuropathological changes in diseases caused by inborn errors of metabolism (L. Crome). The second part deals with a few specific conditions. R. G. Westall's detailed description of the successful treatment of an infant with Maple Syrup Disease is particularly valuable and indeed indispensable for the pædiatrician who at very short notice may have to design a diet containing a reduced amount of the three branched-chain aminoacids.

The editors, and the publishers, are to be congratulated on bringing out this volume so cheaply and within a few months of the meeting.

\section{A Practical Manual for the Treatment of Burns}

Eli Rush Crews, M.D., M.S. Pp. xiii +399 , illustrated. Springfield, Illinois: Charles C. Thomas. 1964. 6 dollars 75 cents.

Dr. Crews has been interested in the management of burns for many years and this is amply demonstrated by the wealth of practical detail mentioned in his book.

His two aims are, to "instruct the surgical residents and also to acquaint Surgeons, General Practitioners and Nurses, with major points of treatment and also to enable them to recognise and confront intelligently, the many problems that may arise during the course of treating burned patients". $\mathrm{He}$ has wisely avoided any attempt to describe all the alternative ways of treating burns, instead he has confined himself to one routine method which he practises. For shock he uses electrolyte solutions together with stored plasma, and prefers not to use Dextran. When other methods of treatment have failed to reverse "renal shutdown" he 